\title{
Eye Detection System Based on Image Processing for Vehicle Safety
}

\author{
Almira Budiyanto ${ }^{1}$, Abdul Manan ${ }^{2}$, Elvira Sukma Wahyuni ${ }^{3}$ \\ 1,2,3Program Studi Teknik Elektro, \\ Fakultas Teknologi Industri, \\ Universitas Islam Indonesia, Yogyakarta \\ 12almira.budiyanto@uii.ac.id, ${ }^{2} 114524080 @ s t u d e n t s . u i i . a c . i d$, \\ 3elvira.wahyuni@uii.ac.id
}

\begin{abstract}
The more advanced the technology and the greater the community's need to carry out activities every day, the number of vehicles on the highway is getting crowded. From year to year, the greater the level of traffic accidents caused by many factors, among the usual reasons is the loss of awareness of the driver when driving a vehicle especially drowsiness. One of the drowsiness parameters is the frequency eye blinks. Therefore, to get the drowsiness symptoms, the purpose of this research is to detect the eye blinks, which in turn reduce the level of accidents by detecting sleepy eyes based on digital image processing. The method used to detect both eyes is the Viola-Jones method. The detection of both eyes can also acquire the duration of closed eyes and the number of eye blinks. A person can be said to be sleepy by means of sleepiness parameters determined by a study. The research shows that detection of eye blinks using the Viola-Jones method has a fairly high accuracy of up to $84.72 \%$ if the face condition is upright and tilted no more than 45 degrees. Another conclusion is that eye detection and driver detection are more effective at certain light intensity values which are around 2-33 lux.
\end{abstract}

Keywords: image processing, Viola-Jones, eye detection, vehicle, safety

\section{Introduction}

The number of vehicles in Indonesia is increasing from year to year, because of the needs of the people who continuously need to move. From many of these vehicles, people are not careful while driving vehicles. There are also more accident rates in Indonesia from public transportation to private vehicles. Based on data available from the past four years, namely from 2014 to 2018, the accident rate continues to increase significantly. Compared to the previous year, from 2012 to 2013, the level of traffic accidents has decreased [1].

Previous research estimates that traffic accidents about 10 to 30 percent were happened due to drowsiness or fatigue while driving a vehicle. Various studies have been carried out by identifying how appropriate and effective ways to find out the driver is sleepy. In many studies to find sleepy eyes, eye blinking is a favorite method conducted by researchers. Other studies suggest that sleepiness can be more disruptive in driving a vehicle compared to alcohol. In an American Automobile Association institution in the United States estimates 40 percent admitted that they fell asleep while driving a vehicle. Of the various accidents that have occurred, one of the most serious 
reasons is lack of sleep. Previous research revealed that there are indicators of someone in a state of drowsiness while driving, namely: repeated blinking of eyes, longer blinking of eyes, nodding of the head, difficulty in keeping the eyes open, and a person's daydreams. Driving while sleepy is a serious thing because it can pose many risks such as traffic accidents [2]-[5].

\section{Literature Review}

\subsection{Literature Study}

Vehicle safety is an interested and popular topic for researchers. Many kinds of research discuss the detection of the driver's condition which shows the abnormal condition leads to accident possibility. There are some parameters to investigate the driver condition, namely eye blinking, heartbeat, taking eyes off the road, alcohol consumption, frequency of eyebrows movement, and the steering angle. While to monitor the vehicle situation, the parameters are engine temperatures, presence of harmful gases, obstacle distance, vehicle location, and time of driving. There are many sensors were used to detect and monitor both driver and vehicle situations. Many studies also use the new Electroencephalography (EEG)-based to detect the unusual driver condition to avoid traffic accident. The studies analyze the signal of EEG and give the braking command [6]-[9].

There are some studies to detect sleepiness, but the method used is not by image processing. The method used in this study is utilizing four sensors installed in a watch or can also be called a smartwatch. The four sensors which are used are a heart rate sensor, pedometer, gyroscope, and accelerometer. The four sensors collected into data that can conclude whether the driver must rest or the driver is tired or not. There is also driver's condition information sharing by Internet of Things (IoT). For post-accident handling, the research implement the GPS and GSM technology to inform the hospital and people nearby about the accident. The accident is detected by the accelerometer, seat belt sensor, vehicle black box, eye blink sensor, and vibration sensors in the vehicle [10]-[13].

The research carried uses a viola-jones method to investigate drowsiness, it uses a variety of many sample images to be used as research material such as 22 human face images and other images in the form of animal faces as many as 8 pieces. To detect the faces, the researchers using MATLAB software and also openCV. Another research uses Eye Aspect Ratio (EAR) which characterizes eye-opening. In another study, a different method was carried out, namely the bwarea method. To find out whether the eyes are sleepy or not, the parameters performed are based on the range of bwarea values. In that study, bwarea when sleepy was valued at 0-299999 and when the condition of the eyes was not sleepy bwarea value exceeded 299999 [14]-[16].

\subsection{Sleepiness Parameters}

Drowsiness is a time when someone can be said to be tired or unconscious so that the body will experience rest. A study conducted by Tecee, sleepiness parameters can also be detected with blinking frequency. The average blink of an eye when the body is normal is around 15 to 20 times per minute. The frequency of blinking can decrease when reading about 3 times per minute and when the eyes need to close or when a person's condition is stressed, the blinking frequency will increase. A study divides the parameters of sleepiness based on the duration of the eye blink. At the time of normal blinking eyes for 
an average of $75 \mathrm{~ms}$ to $400 \mathrm{~ms}$, so it can be defined the normal eye duration limit is $400 \mathrm{~ms}$ and if the blink duration is longer than $400 \mathrm{~ms}$ it can be said to be sleepy [17]-[19].

\subsection{Viola-Jones Method}

Detecting an image may use many methods, but the method used in this study is popular enough to detect your face and eyes using Viola-Jones. This method was proposed by several people namely Paul Viola and Michael Jones in 2001 [20]. To get the detection of the object, it is done by combining 4 concepts, namely:

- Haar feature

- Integral Image

- Adaboost machine learning

- Multilevel Classifiers

\section{Research Method}

\subsection{Tools and Materials}

The following is an overview of the system design that will be made to detect drivers who indicated sleepy while driving on Fig. 1.



Fig 1. Instrument design

Fig 1 can explain an explanation about the process of how these systems work. Starting from the input in the form of an image then processed which will ultimately be known whether the driver is detected sleepy or not by using parameters in the form of the number of blinks and the duration of closing the eyes.

Before conducting research there are several tools and materials used to make this drowsiness detection system:

- A computer used to process image/video data in real-time,

- A webcam camera, mounted on a laptop to get image/video data,

- OpenCV, image processing library,

- Python, the programming used in a sleep detection system. 
The flow diagram in Fig. 2 illustrates a general description of the flow of a sleepy detection system it can work. First, the first step is to take real-time video taken from a webcam camera on a laptop which is then processed by a computer. Then the second step is detecting the face with the Viola-Jones method captured by the webcam. After the system detects the face, then it detects both eyes. The third step is if the eye is not detected or it can be said that the eye is closed then the program will calculate the eye's duration. In addition to detecting duration, this study also uses the parameter number of blinks per minute. So in this study, there are two parameters, namely the duration of closing the eyes and the number of blinks per minute.

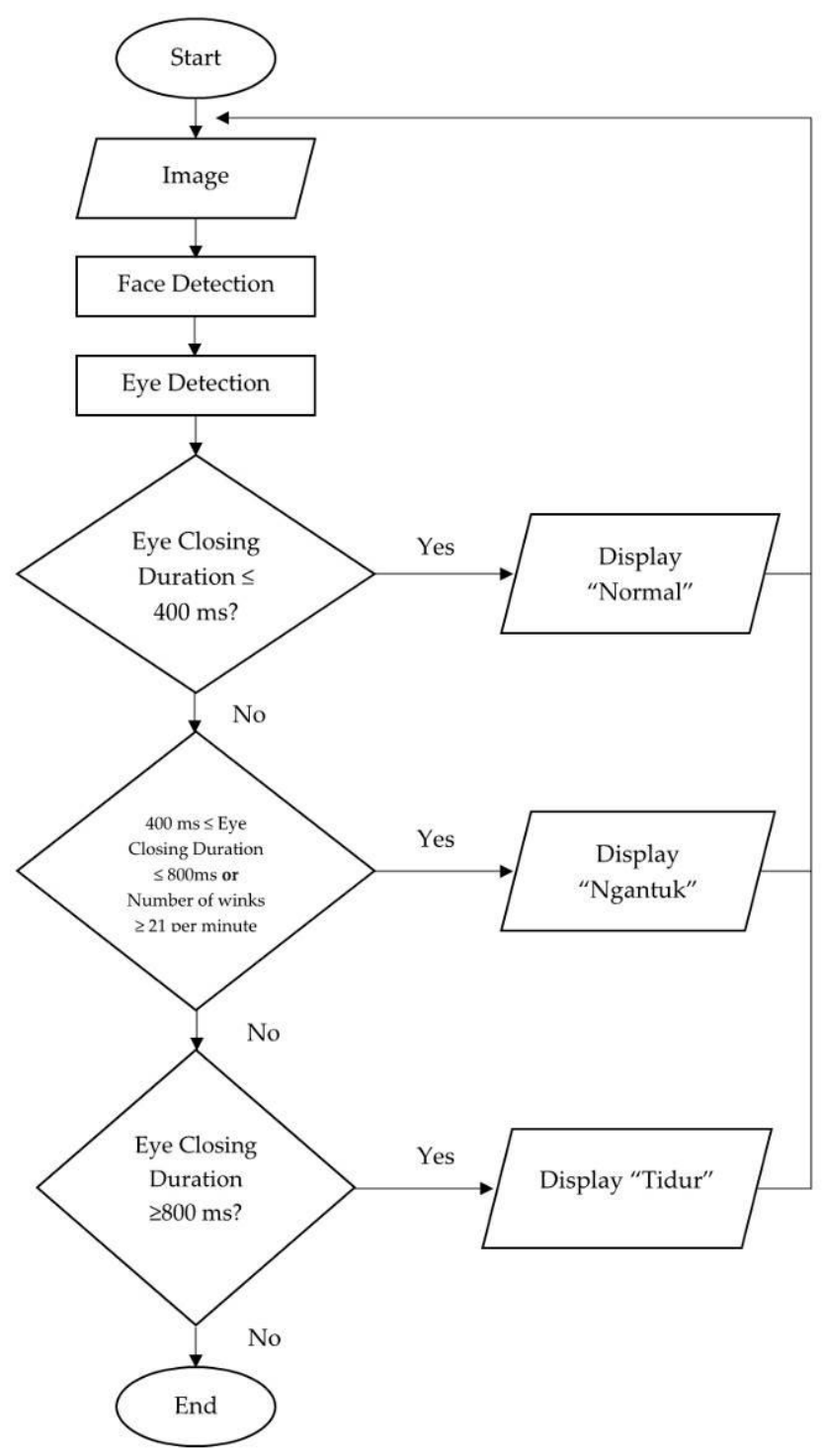

Fig. 2. Work diagram

\subsection{Eye Parameter and Detection}

The parameters used to detect drowsiness based on the duration of eyes closing, Table 1 explains the parameters of drowsiness based on a study conducted by Phillip. P. Caffier: 


\begin{tabular}{|c|c|}
\multicolumn{2}{|c|}{ Table 1. Duration of eyes closing } \\
\hline Eye Status & Program \\
\hline Normal & The duration of the eyes closing $<400 \mathrm{~ms}$ \\
\hline $\begin{array}{c}\text { Sleepy } \\
\text { Ngantuk) }\end{array}$ & $\begin{array}{c}\text { The duration of the eyes closing }>400 \mathrm{~ms} \text { and } \\
\text { the duration of the eyes closing }<800 \mathrm{~ms}\end{array}$ \\
\hline $\begin{array}{c}\text { Sleep } \\
\text { (Tidur) }\end{array}$ & The duration of the eyes closing $>800 \mathrm{~ms}$ \\
\hline
\end{tabular}

This study divides the status into three different conditions, namely normal eye conditions, drowsiness and when the condition of the driver falls asleep according to Table 1. Table 1 explains when the duration of closing the eyes is smaller than $400 \mathrm{~ms}$ then the eyes are said to be normal or not sleepy. When the closing time of the eye is greater than $400 \mathrm{~ms}$ and if the closing time of the eye is less than 800 milliseconds, the driver can be said to be sleepy or "ngantuk" (Bahasa). Then, if the duration of eyes closing is greater than 800 milliseconds, the status of the driver is sleep or "tidur" (Bahasa) [4].

Besides using the duration of eyes closing, the second parameter is to use the number of blinks. Based on the research that is carried out by Tecce in the year 1992 about the blinking number of the eyes of humans, can be differentiated into several conditions. At the time of normal eye conditions, the number of blinks as much as 15-20 minutes. Then when people being under conditions of stress, depressed or when need eyes to close, the blink frequency would further increase compared with the eyes in normal condition. On the contrary, while a person's being read, the number of blinks will decline compared to the normal condition [18]. This study classifies the retrieval data into the awareness of the driver based on the duration of eyes closing and the number of blinks. Fig. 3 is the interface that is used in this research.

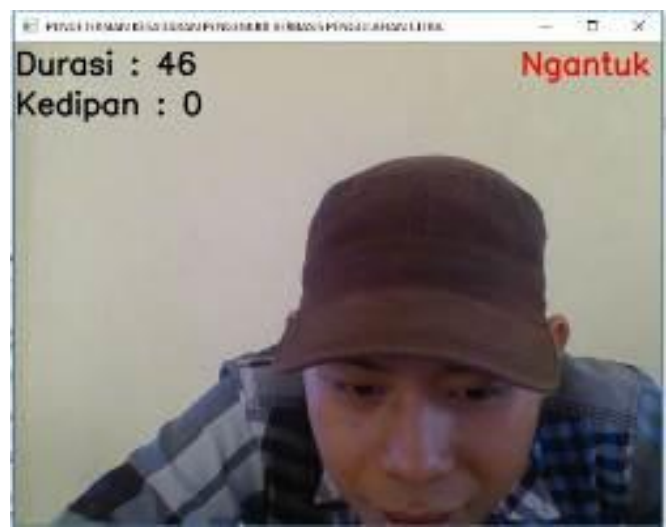

Fig. 3 Sleepiness detection interface

There are three pieces of information that can be retrieved from the interface. The first is in the upper left corner showing the value of the duration of eyes closing of "Durasi" (Bahasa), if the eyes are closed it will display the value. While in the second line, the interface displays information about the number of blinks or "Kedipan" (Bahasa), the value of the blinking will increase following the number of driver's blinks. Then the latter is information about the status of the driver that is located on a part of a corner right on, the status will show information if the driver drowsiness. 


\section{Result and Analysis}

\section{1. $\quad$ Eye Detection Result Based-on Wearing Object}

In this experiment, it is important to do as the first step of detection which aims to detect the eyes of both motorists whether they are detected or not. Fig 4 shows the various conditions of the people based on wearing objects.



(a)

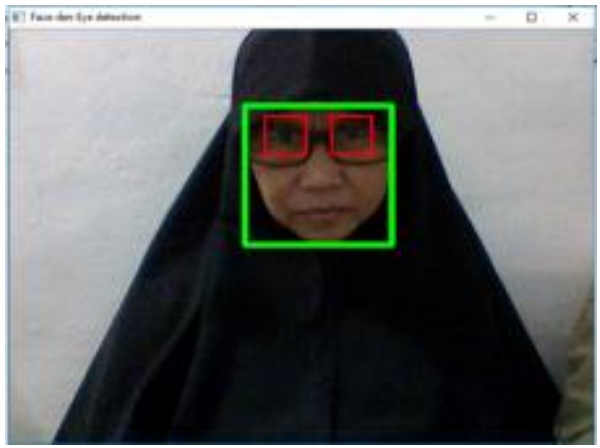

(c)

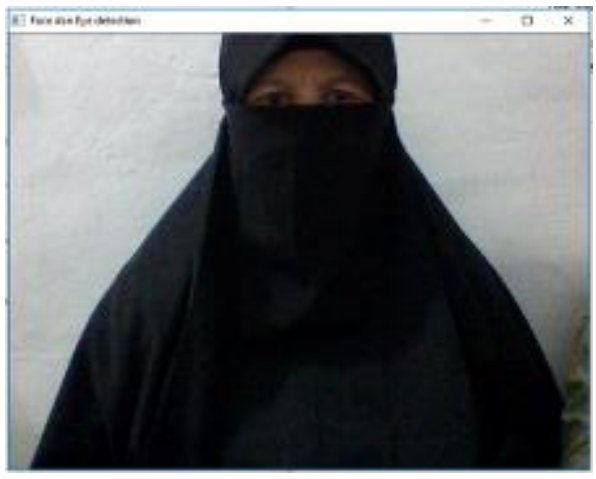

(b)

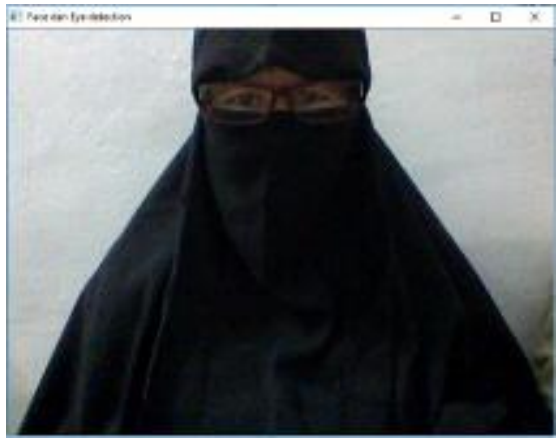

(d)

Fig 4. Eye detection with veiling-wearing

Fig 4 (a) is an eye detection test when the driver uses a veil, the results obtained by the face can be purchased 100\% with 10 trials. On the other hand, Fig 4 (b) illustrates when the driver uses the mask, the system cannot detect the eye or detected $0 \%$, due to incompatible with haar like features. In the experiments using the veil and glasses seen in Fig 4 (c), the eye detection test was detected $100 \%$ when there was no reflection of light, but the eye was not detected due to reflected light from the glasses. In testing when the driver uses a veil, mask, and glasses as seen in Fig 4 (d), the eye is detected $0 \%$ of 10 times.

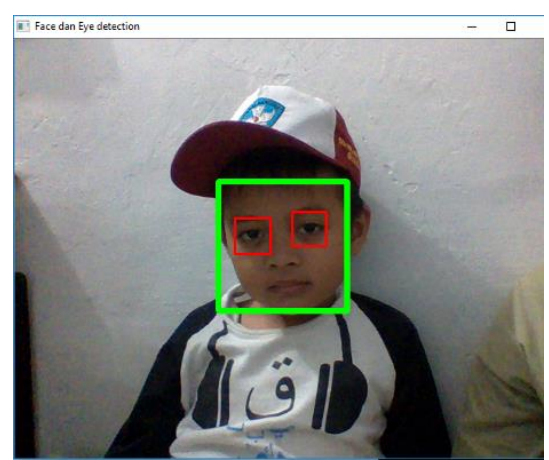

Fig 5. Eye detection with hat-wearing 
As can be seen in Fig 5, the eye detection test when people using a hat, the eye can be detected $100 \%$ clearly because the face is visible as a face without a hat.

\subsection{Eye Detection Result Based on Head Position}

This test is carried out to determine whether when the driver looks down or turns around, the driver's eyes can be detected or not. Fig 6 explains some conditions when people looking up, looking left, looking down, and looking right:

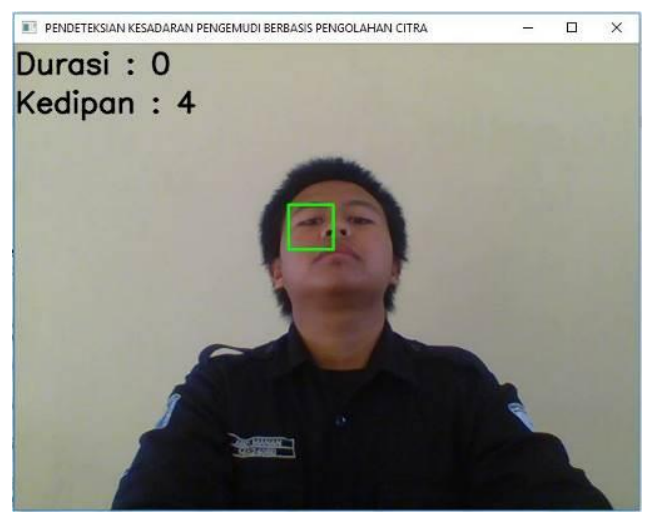

(a)



(c)



(b)

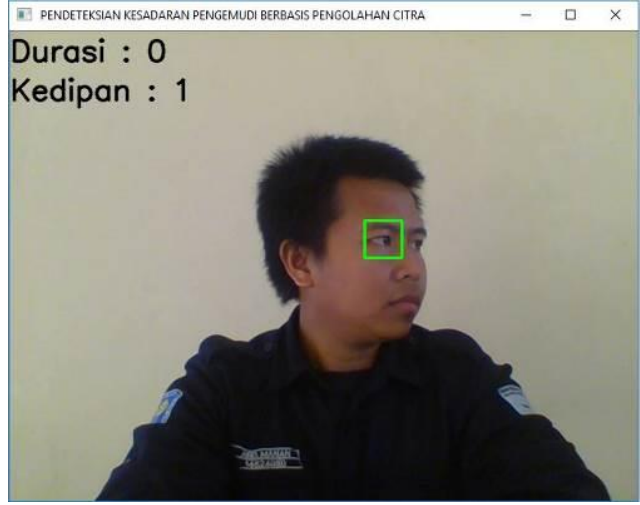

(d)

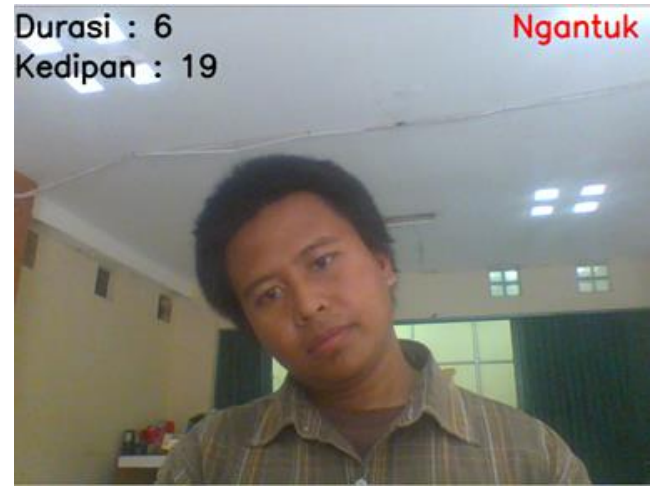

(e)

Fig 6. Eye detection based on head position

Fig 6 (a) on the condition of the head looking up which is cannot be detected properly because visually can not be seen clearly. While the head looking left as can be seen in Fig 
6 (b), the eye cannot be detected properly. Like head looking up and left, while head bowing and looking right as in Fig 6 (c) and Fig 6. (c), the eye also cannot be detected properly. Fig 6 (e) is a tilted face also cannot be detected properly because it does not fit the haar like feature used by Viola-Jones. So the research conducted now is limited by the condition of the driver in an ideal position such as an upright face looking forward and not looking too right and left.

\subsection{Eye Detection Result Based-on Light Position}

This test is done depend on the variation of image lighting. Fig 7 shows several lighting conditions:

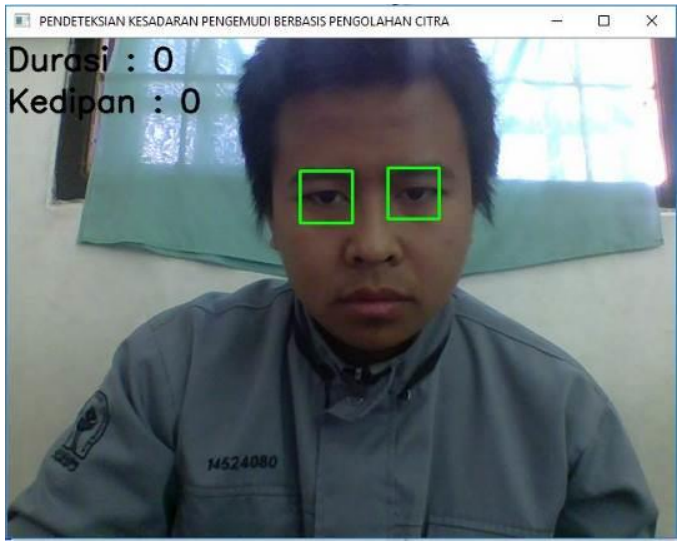

(a)

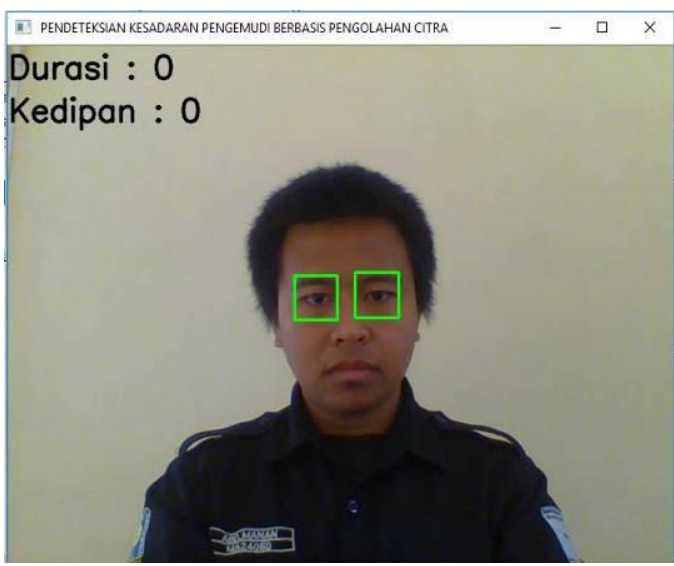

(c)

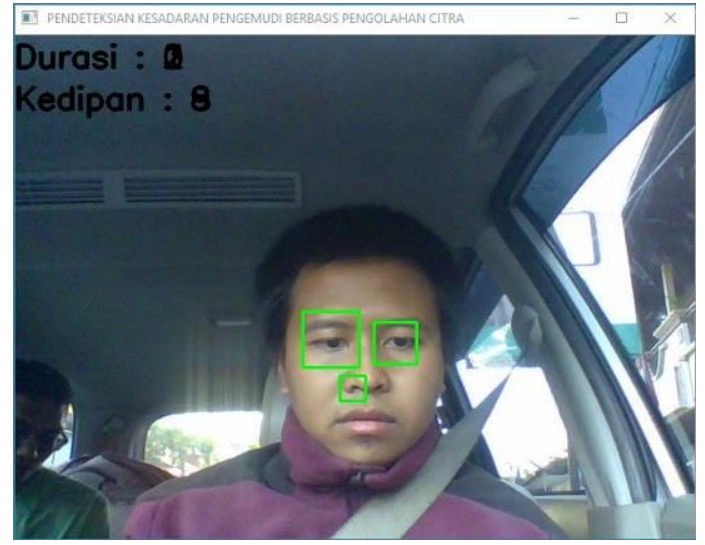

(b)

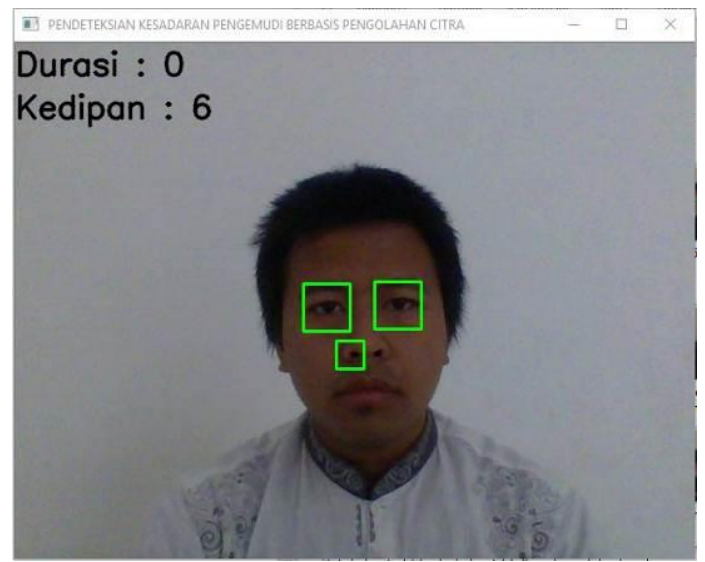

(d)

Fig 7. Eye detection based on light

In the first condition as shown in Fig 7 (a) when the lighting looks dazzled or unstable, the eye is detected irregularly. In the second condition seen in Fig 7 (b) testing carried out in the car in the afternoon. It can be concluded that the lighting conditions while driving can also be said to be unstable because it is dazzled and this condition is almost the same as the first condition. In the third condition as shown in Fig 7 (c) is the condition when lighting is stable, concluded that such conditions are the best conditions for testing because stable light causes the computer to work normally but it is difficult to detect whether the eyes are closed or open. Then in Fig 7 (d) is the last condition when stable light is not too bright and not too dark in a $3 \mathrm{~m} \mathrm{x} 3 \mathrm{~m}$ room at $8 \mathrm{am}$ to $9 \mathrm{am}$, in this condition it is a good condition to detect whether the eyes are closed or open. 


\subsection{Testing Number of blinks}

This step explains testing counting the number of eye blinks which is carried out in light conditions with different cameras. To detect the light intensity, the Android lux meter application is used in this test. Sometimes the Lux meter reads well and sometimes it is quite accurate for example in the range of light values of 3-4 lux, 7-9 lux, 11-15 lux, and 35-37 lux. Fig. 8 examines the duration of a closing eye and the number of blinks test.

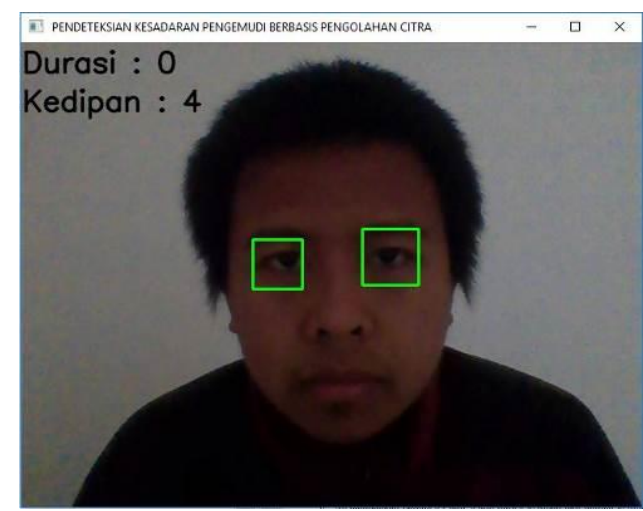

Fig. 8. Testing number of blinks and duration of eyes closing

To check the number of blinks, the system is tested whether the system counting is accurate. The test is done with any variation of light intensity from 2 Lux to 37 Lux with 10 trials. Table 2 shows how accurate the system detects the number of blinks in $30 \mathrm{~cm}$ distance. While Fig 9 illustrates the average percentage of test success.

Table 2. Blink detection result

\begin{tabular}{|c|c|c|c|c|c|c|}
\hline Trial- & 2 Lux & $3-4$ lux & $7-9$ lux & $11-15$ lux & 26 lux & $35-37$ Lux \\
\hline 1 & $72,5 \%$ & $97,5 \%$ & $97,5 \%$ & $85 \%$ & $87,5 \%$ & $55 \%$ \\
\hline 2 & $30 \%$ & $82,5 \%$ & $97,5 \%$ & $95 \%$ & $95 \%$ & $60 \%$ \\
\hline 3 & $85 \%$ & $82,5 \%$ & $87,5 \%$ & $87,5 \%$ & $100 \%$ & $40 \%$ \\
\hline 4 & $90 \%$ & $67,5 \%$ & $100 \%$ & $97,5 \%$ & $87,5 \%$ & $55 \%$ \\
\hline 5 & $97,5 \%$ & $80 \%$ & $90 \%$ & $87,5 \%$ & $90 \%$ & $45 \%$ \\
\hline 6 & $85 \%$ & $90 \%$ & $80 \%$ & $95 \%$ & $90 \%$ & $52,5 \%$ \\
\hline 7 & $90 \%$ & $87,5 \%$ & $100 \%$ & $92,5 \%$ & $100 \%$ & $47,5 \%$ \\
\hline 8 & $87,5 \%$ & $75 \%$ & $87,5 \%$ & $72,5 \%$ & $95 \%$ & $47,5 \%$ \\
\hline 9 & $95 \%$ & $67,5 \%$ & $97,5 \%$ & $95 \%$ & $90 \%$ & $55 \%$ \\
\hline 10 & $85 \%$ & $77,5 \%$ & $92,5 \%$ & $85 \%$ & $92,5 \%$ & $45 \%$ \\
\hline Average & $81,75 \%$ & $80,75 \%$ & $93 \%$ & $89,25 \%$ & $92,75 \%$ & 50,75 \\
\hline
\end{tabular}




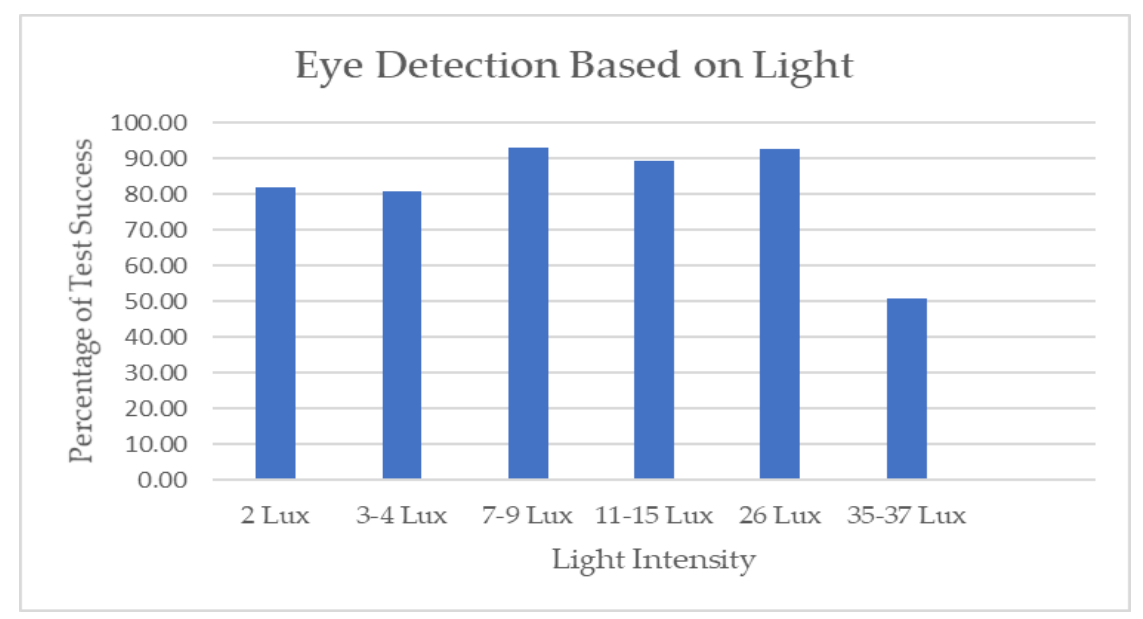

Fig 9. Number of blink tests based on light intensity

Fig 9 can explain that the effective light intensity is 2-33 lux at a distance of $30 \mathrm{~cm}$. Then the lower limit for detecting eyes blink is at 2 lux and the upper limit for detecting blinking is 33 lux because values below 2 lux and above 33 lux cannot detect eyes blinks, or the number of blinks is erratic.

\subsection{System Test Result}

Fig. $10 \mathrm{a}, \mathrm{b}$, and c respectively displays the interface if the driver is normal, drowsy (ngantuk), and sleep (tidur).

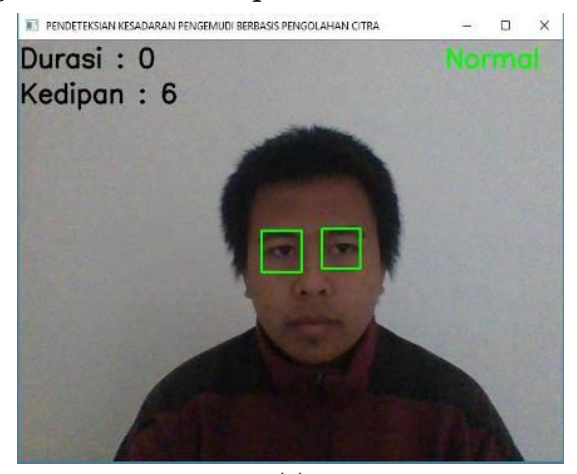

(a)



(b)

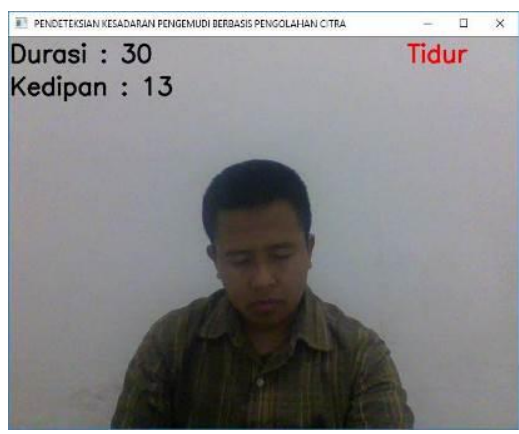

(c)

Fig. 10. System test result

Based on the test result, the light greatly influences blink detection and calculates duration. Successful detection with a percentage of $97.5 \%$ in light $7-9$ lux with a distance of $30 \mathrm{~cm}$. Can be seen from Fig. 10 (a) is the display during normal conditions it will 
display "Normal". While Fig. 10 (b) is the display when the driver is sleepy, and the alarm will display "Ngantuk". Then the last is Fig. 10 (c) when the condition is asleep. After experimenting 10 times, when the driver is sleepy or asleep the system detects $100 \%$ correct according to the conditions of the blink and duration.

\section{Conclusion}

After researching to detect sleepiness with the image processing method with a webcam on a laptop, it is found that detection of eye blinks using the Viola-Jones method has a fairly high accuracy of up to $84.72 \%$ if the face condition is upright and tilted no more than 45 degrees. In addition, eye detection and driver detection are more effective at certain light intensity values which are around 2-33 lux.

\section{References}

[1] B. P. Statistik, "Perkembangan Jumlah Kendaraan Bermotor Menurut Jenis," 2019. [Online]. Available: https://www.bps.go.id/linkTableDinamis/view/id/1133. [Accessed: 14-Mar-2019].

[2] B. P. Statistik, “Jumlah Kecelakaan, Koban Mati, Luka Berat, Luka Ringan, dan Kerugian Materi yang Diderita Tahun 1992-2018," 2019. [Online]. Available: https://www.bps.go.id/linkTableDinamis/view/id/1134. [Accessed: 14-Mar-2019].

[3] M. Hafil, “Jumlah Kecelakaan di Indonesia Empat Tahun Terakhir," 2018. [Online]. Available:

https://nasional.republika.co.id/berita/nasional/umum/17/05/02/opaywe326-jumlahkecelakaan-di-indonesia-empat-tahun-terakhir. [Accessed: 03-Apr-2018].

[4] S. Dhiraj Sunehra and K. Jhansi, "Implementation of Microcontroller Based Driver Assistance and Vehicle Safety Monitoring System," in 2015 International Conference on Information Processing (ICIP), pp. 423-428, 2015.

[5] P. Chaisiriprasert and K. Yongsiriwit, "Surveillance System for Abnormal Driving Behavior Detection," in 2019 4th International Conference on Information Technology (InCIT), pp. 155-158, 2019.

[6] J. P. Vasconez and F. A. Cheein, "Sleepiness Detection for Cooperative Vehicle Navigation Strategies," in 2018 5th International Conference on Control, Decision and Information Technologies (CoDIT), pp. 940-945, 2018.

[7] D. Mashru, "Detection of a Drowsy state of the Driver on road using wearable sensors: A survey," in 2018 Second International Conference on Inventive Communication and Computational Technologies (ICICCT), pp. 691-695, 2018.

[8] Y. Ma, S. Qi, L. Fan, W. Lu, C. Chan, and Y. Zhang, "Dynamic Bayesian Network Approach to Evaluate Vehicle Driving Risk Based on On-Road Experiment Driving Data," IEEE Access, vol. 7, pp. 135050-135062, 2019.

[9] T. Teng and L. Bi, "A Novel EEG-based Detection Method of Emergency Situations for Assistive Vehicles," in Seventh International Conference on Information Science and Technology, pp. 335-339, 2017.

[10]S. Ríos-aguilar, J. Luis, M. Merino, A. M. Sánchez, and Á. Sánchez, “Variation of the Heartbeat and Activity as an Indicator of Drowsiness at the Wheel Using a Smartwatch," Int. J. Interact. Multimed. Artif. Intell., vol. 3, no. 3, pp. 96-100, 2015. 
[11]S. Samson and A. S. Oliver, "Analyzing Abnormalities While Driving To Avoid Accidents," in 2019 Fifth International Conference on Science Technology Engineering and Mathematics (ICONSTEM), vol. 1, pp. 187-191, 2019.

[12]S. Nanda, "An IOT Based Smart System for Accident Prevention and Detection," in 2018 Fourth International Conference on Computing Communication Control and Automation (ICCUBEA), pp. 1-6, 2018.

[13] C. Mohamedaslam, T. A. Roshan, M. T. M. Sahal, N. A. Najeeb, and K. Nisi, "A Smart Vehicle for Accident Prevention Using Wireless Blackbox and Eyeblink Sensing Technology Along with Seat Belt Controlled Ignition System," in 2016 Online International Conference on Green Engineering and Technologies (IC-GET) A, 2016.

[14]M. D. Putro, T. B. Adji, and B. Winduratna, "Sistem Deteksi Wajah dengan Menggunakan Metode Viola-Jones," in Seminar Nasional Science, Engineering, and Technology, pp. 1-5, 2012.

[15]I. Chatterjee and A. Sharma, "Driving Fitness Detection: A Holistic Approach For Prevention of Drowsy and Drunk Driving using Computer Vision Techniques," in 2018 South-Eastern European Design Automation, Computer Engineering, Computer Networks and Society Media Conference (SEEDA_CECNSM), pp. 1-6, 2018.

[16]E. P. Poli, A. S. M. Lumenta, B. A. Sugiarso, and J. O. Wuwung, “Deteksi Rasa Kantuk pada Pengendara Kendaraan Bermotor Berbasis Pengolahan Citra Digital," J. Tek. Elektro dan Komput., vol. 2, no. 2, pp. 1-6, 2013.

[17]A. S. Houssaini, "Real-Time Driver' s Hypovigilance Detection using Facial Landmarks," in 2019 International Conference on Wireless Technologies, Embedded and Intelligent Systems (WITS), pp. 1-4, 2019.

[18]I. Hedrian, M. Rivai, and D. Purwanto, "Implementasi Stimulus Aromatik Pada Pengemudi Berdasarkan Deteksi Kantuk," Institut Teknologi Sepuluh November, 2012.

[19] A. Das, A. Ray, A. Ghosh, and S. Bhattacharyya, "Vehicle Accident Prevent cum Location Monitoring System," in 2017 8th Annual Industrial Automation and Electromechanical Engineering Conference (IEMECON), pp. 101-105,2017.

[20]P. Viola, "Rapid Object Detection using a Boosted Cascade of Simple Features," in Proceedings of the 2001 IEEE Computer Society Conference on Computer Vision and Pattern Recognition. CVPR 2001, 2001. 